\title{
Thermotropic effects of PEGylated lipids on the stability of HPPH-encapsulated lipid nanoparticles (LNP)
}

\author{
Poornima Kalyanram ${ }^{1} \cdot$ Anu Puri $^{2} \cdot$ Anju Gupta $^{1}$
}

Received: 8 March 2021 / Accepted: 30 May 2021 / Published online: 26 June 2021

(c) Akadémiai Kiadó, Budapest, Hungary 2021

\begin{abstract}
In this work, we demonstrate the enhanced thermal and steric stability of lipid-based formulations in the presence of encapsulated HPPH that have demonstrated potential cancer applications in previously presented in vivo studies. Differential scanning calorimeter (DSC) was used to study the phase transitions, and domain formations, and to qualify the thermodynamic properties associated with change in lipid bilayer behavior due to the presence of PEGylated at varying concentrations and sizes, and the encapsulated HPPH molecules. Thermal instability was quantified by dramatic changes in calculated enthalpy, and the shape of the melting peak or calculated half width of melting peak. This systematic study focused on understanding the effects of varying molecular mass and concentrations of PEG polymers in the photopolymerizable lipid $\mathrm{DC}_{8,9} \mathrm{PC}$ lipid bilayer matrix for four weeks at room temperature of $25^{\circ} \mathrm{C}$. The major findings include increased thermal stability of the lipid bilayer due to the presence of PEG-2 K and the HPPH that resulted from the van der Waals forces between various molecular species, and the change in bilayer curvature confirmed via mathematical correlations. It is demonstrated that the encapsulation of therapeutics in lipid formulations can alter their overall thermal behavior, and therefore, it is imperative to consider calorimetric effects while designing lipid-based vaccines. The presented research methodologies and findings presented can predict the stability of lipid-based vaccines that are under development such as COVID-19 during their storage, transport, and distribution.
\end{abstract}

Keywords Lipids $\cdot$ Thermal analysis $\cdot$ Thermodynamics $\cdot$ Vaccine $\cdot$ Cancer

\begin{tabular}{|c|c|}
\hline \multicolumn{2}{|c|}{ Abbreviations } \\
\hline DSC & Differential scanning calorimetry \\
\hline LNP & Lipid nanoparticles \\
\hline PEG & Polyethylene glycol \\
\hline HPPH & $\begin{array}{l}\text { 2-[1-Hexyloxyethyl]-2-devinyl } \\
\text { pyropheophorbide-a }\end{array}$ \\
\hline DSPE-PEG & $\begin{array}{l}\text { 1,2-Distearoyl-sn-glycero-3-phosphoethan- } \\
\text { olamine-N-[amino(polyethylene glycol) }\end{array}$ \\
\hline DLS & Dynamic light scattering \\
\hline $\mathrm{DC}_{8,9} \mathrm{PC}$ & $\begin{array}{l}\text { 1,2-Bis(10,12-tricosadiynoyl) )-sn-glycero- } \\
\text { 3-phosphocholine }\end{array}$ \\
\hline PDI & Polydispersity index \\
\hline DMSO & Dimethyl sulfoxide \\
\hline
\end{tabular}

Anju Gupta

anju.gupta@utoledo.edu

1 Department of Mechanical, Industrial and Manufacturing Engineering, University of Toledo, Toledo, OH 43606, USA

2 RNA Biology Laboratory, National Cancer Institute At Frederick, Frederick, MD 21702, USA
COVID
Corona virus disease
FDA
Food and drug administration

\section{Introduction}

Liposomes or lipid nanoparticles (LNPs) are the self-assemblies of lipids in aqueous environment, and the presence of hydrophobic and hydrophilic regions makes them ideal candidates for the encapsulation of a variety of therapeutic molecules [1-9]. However, liposomes are susceptible to leakage and aggregation because of hydrolysis and oxidation of lipids [10], and therefore, the physical stability of liposomes becomes an important consideration for their applications as drug carriers [11,12] and vaccines [13-15]. The hydrophilic headgroup and the hydrophobic acyl chain length of the constituent lipids determine the overall packing behavior, surface charge, and the interfacial stability of the liposomes or lipid nanoparticles (LNPs) [16, 17]. The packing parameter $(\mathrm{P})$ of the constituent lipids is defined as 
$P=\frac{V}{S L_{\mathrm{C}}}$

where $V$ is the hydrophobic volume, $S$ is the surface area of the occupied by the polar region, and $L_{\mathrm{c}}$ is the extended length of the hydrophobic tail chain[18-20]. Therefore, the choice of the constituting lipid governs the thermal stability owing to the melting, and other temperature-dependent characteristics of the lipids which attributes to the leakiness of the lipid bilayer. Lipid membrane leakage is undesirable because it decreases the efficacy and shelf life of liposomes [21-23]. An approach to overcome this leakage is to modify the acyl tails by introducing light-sensitive polymerizable moieties [24-26]. The cross-linked acyl tails in the presence of light of a suitable wavelength changes conformation to release the contents in the organ of interest [27, 28]. In the absence of the light, the links in the acyl chain do not change conformation and prevent the leakage of contents $[29,30]$. Furthermore, steric stabilization or prevention of aggregation can be induced by introducing polymers and block co-polymers such as polyethylene glycol (PEG), polyvinyl alcohol (PVA) [31, 32], polylactic acid (PLA) [33, 34], and polyglycolic acid (PGA) polymers [35-38] on the liposome surface and the outer lipid leaflet. Amongst these, only PEG polymer has shown an efficient and lasting steric stabilization which is also approved by the FDA [36, 38, 39].

$\mathrm{DC}_{8,9} \mathrm{PC}$ [1,2-bis(10,12-tricosadiynoyl)-sn-glycero3-phosphocholine] is photopolymerizable lipid consisting of polymerizable diacetylene linked to the tail chains [40] that results in tubule-like self-assemblies in an aqueous environment [41, 42]. However, when present in the presence of matrix phospholipids such as DPPC or other polymeric lipids like DSPE-PEG, $\mathrm{DC}_{8,9} \mathrm{PC}$ forms vesicle-like structures. The diacetylene bonds present in the tail chains of the vesicles or liposomes upon photoactivation changes conformation (from cis to trans) to release the encapsulated content to the target location [29, 43-46]. Our recent work involving PEGylated-DSPE lipids along with $\mathrm{DC}_{8,9} \mathrm{PC}$, resulted in formation of stable vesicular lipid nanoparticles (LNP's) in the nanometer size range of $99-110 \mathrm{~nm}$ [47]. This unique lipid packing was found to be dependent on the mole ratios of the pegylated lipids (DSPE-PEG), with optimal concentrations of up to $20 \mathrm{~mol} \%$. The LNP's composed of this polymeric, $\mathrm{DC}_{8,9} \mathrm{PC}$ along with DSPE-PEG2000 successfully encapsulated of the photodynamic therapy (PDT) drug, 2-[1-hexyloxyethyl]-2-devinyl pyropheophorbide-a (HPPH), a well-known hydrophobic photosensitizer at relatively high concentrations. These liposomal carriers and HPPH demonstrated faster skin clearance and deeper tumor penetration at lower dosage rates as opposed to various other FDA approved photosensitizers [48-50] in addition to their stability at room temperatures. The HPPH-loaded LNPs exhibited remarkable PDT efficiency and animal survival rates during the clinical trials [47], with potential biomedical applications in enhanced drug delivery $[47,51]$.

Sterically, the inclusion of hydrophilicity through PEGylated lipids in LNPs induces stealth protection and stabilization preventing the attachment of macromolecules from the blood stream, thereby resisting phagocytosis [52-56]. PEGylation also increases the packing order in the headgroup and the bilayer region [57-60]. It is also assumed that PEG molecules attract water and subsequently form a steric barrier against the adherence of other macromolecules [61-63]. The PEGylated lipids usually assume mainly two conformations namely mushroom and brushes within the lipid bilayer based on their density. At lower PEG concentrations, the lipid head groups do not interact and follow random configurations, described as mushroom configurations. In contrast at high concentrations of PEG lipids, the surface-associated mushrooms begin to overlap and transitions to brush conformations which results in expansion of membrane area due to the lateral pressure exerted by the brush conformations [8, 64-66].

Differential scanning calorimetry (DSC) has been extensively used to study the thermal transitions in a lipid bilayer or the fluidity along with gaining insights on the effects of encapsulation, thermal stability and stresses of the liposomes undergoing temperature variations, particularly under the localized heating environment created during photoactivation of liposomes [67-71]. The presence of encapsulated material in the bilayer region is detected by DSC via formation of domains and changes in the shape of the melting peak such as broadening, temperature shifts [72-75]; and the thermal stresses are observed via annealing of the liposomal formulations through multiple heating and cooling cycles at a wide range of temperature $[1,2,5,76]$.

In this study, we investigated the steric and thermal stabilization effects exerted by the varying concentrations and molecular mass of DSPE-PEG lipid in $\mathrm{DC}_{8,}{ }_{9} \mathrm{PC}$ lipid matrix. An extensive thermal analysis of the liposomal formulation demonstrated phase changes and segregation within the lipid bilayer due to the presence of encapsulated HPPH molecules. Additionally, correlations between theoretical quantified thermotropic properties such as enthalpy $(\Delta H)$ and transition temperature $\left(T_{\mathrm{m}}\right)$ with regard to thermal stability of the formulations are presented. The novelty of this fundamental work lies in filling the gap in understanding of the effects of size and concentration of PEGylated lipid DSPE-PEG in a lipid bilayer matrix comprising of a photopolymerizable lipid $\mathrm{DC}_{8,9} \mathrm{PC}$. The findings of this work will enable in photo-polymerizable liposomal formulation or lipid nanoparticles for potential photodynamic therapies. 


\section{Experimental}

\section{LNP formulations}

\section{Materials used}

The lipids used in this study were purchased from Avanti Polar Lipids- $\mathrm{DC}_{8,9} \mathrm{PC}$ (1,2-bis(10,12-tricosadiynoyl))-snglycero-3-phosphocholine (cat\# 870,016); DSPE-PEG1000 (1,2-distearoyl-sn-glycero-3-phosphoethanolamine-N[methoxy(polyethylene glycol)-1000] (ammonium salt), cat\# 880,720); DSPE-PEG2000 (1,2-distearoyl-sn-glycero-3-phosphoethanolamine- $\mathrm{N}$-[methoxy (polyethylene glycol)-2000] (ammonium salt), cat \# DSPE-PEG2000)); DSPE-PEG5000 (1,2-distearoyl-sn-glycero-3-phosphoethanolamine- $\mathrm{N}-[$ methoxy(polyethylene glycol)-5000] (ammonium salt), cat \# 880,220). HPPH (2-[1-hexyloxyethyl]2-devinyl pyropheophorbide- $a$ ) was synthesized by Dr. Gary Pauly (Chemistry Core, Chemical Biology laboratory, CCR). HEPES-buffered saline (HBS) buffer of $\mathrm{pH} 7.4$ of reagent grade was used.

\section{Preparation and characterization of LNP's}

LNPs were synthesized using thin-film hydration technique. Briefly, calculated volumes of DSPE-PEG and $\mathrm{DC}_{8,9} \mathrm{PC}$ lipids suspended in chloroform were added in glass tubes to obtain the desired concentration of LNPs. The lipid mixtures were dried under a gentle stream of ultra-high pure (UHP) nitrogen gas to evaporate chloroform, that leaves a thin film of lipids in the bottom of the tubes. The dried films were hydrated with HBS buffer of $\mathrm{pH}$ 7.4. For the HPPHencapsulated LNPs, HPPH solution (in DMSO) were added to the lipid mixtures prior to making the films. LNPs were prepared at $5 \mathrm{mg}$ total lipid/mL in HBS, pH 7.4. Lipid suspensions were subjected to at least 5 freeze-thaw cycles and sonicated using a Probe sonicator (Branson Sonifier, Microtip probe, Fisher Scientific; 5-10 cycles, 1 min per cycle followed by $1 \mathrm{~min}$ of rest) using an ice bath. Upon rehydration, LNPs were uniformly sized by extruding through polycarbonate membrane of pore size $100 \mathrm{~nm}$. Unincorporated HPPH was removed by low-speed centrifugation, and LNPs in the supernatant were analyzed by dynamic light scattering (DLS). Details of various formulations are provided in Table 1 . The concentration of HPPH was decided based on previously performed in vivo studies.

\section{Dynamic light scattering (DLS)}

Liposomal formulations containing PEGylated lipids and $\mathrm{DC}_{8,9} \mathrm{PC}$ were suspended by probe sonication and diluted in HBS at either 1:20 or 1:40 (v/v) ratios. The size, polydispersity index (PDI) and surface charge of both encapsulated and unencapsulated liposomes were analyzed using a Malvern Instruments Zetasizer by dynamic light scattering method at $25^{\circ} \mathrm{C}$ and at $173^{\circ}$ backscatter angle with $120 \mathrm{~s}$ equilibration time for three technical duplicates.

\section{Differential scanning calorimetry (DSC)}

DSC studies were performed on a TA Instruments Q-2000 DSC. $10 \mu \mathrm{L}$ of the sample were placed in T-zero Hermetic pan and sealed using DSC sample press. The samples were
Table 1 Composition of the lipid nanoparticle formulations used in this research (mass ratio)

\begin{tabular}{llll}
\hline $\begin{array}{l}\text { DC }{ }_{8,9} \text { PC: PEGylated } \\
\text { lipid mole ratio }\end{array}$ & Liposomal (LNP) formulation* & PEGylated lipid type & $\begin{array}{l}\text { HPPH encap- } \\
\text { sulation (20:1 } \\
\text { lipid:HPPH) }\end{array}$ \\
\hline $100: 00$ & $\mathrm{DC}_{8,9} \mathrm{PC}$ only & None & No \\
$90: 10$ & $\mathrm{DC}_{8,9} \mathrm{PC} / 1 \mathrm{~K}(10)$ & DSPE-PEG1000 & No \\
$99: 1$ & $\mathrm{DC}_{8,9} \mathrm{PC} / 2 \mathrm{~K}(1)$ & DSPE-PEG2000 & No \\
$95: 5$ & $\mathrm{DC}_{8,9} \mathrm{PC} / 2 \mathrm{~K}(5)$ & $\cdots$ & No \\
$90: 10$ & $\mathrm{DC}_{8,9} \mathrm{PC} / 2 \mathrm{~K}(10)$ & $\cdots$ & No \\
$80: 20$ & $\mathrm{DC}_{8,9} \mathrm{PC} / 2 \mathrm{~K}(20)$ & $\cdots$ & No \\
$50: 50$ & $\mathrm{DC}_{8,9} \mathrm{PC} / 2 \mathrm{~K}(50)$ & $\cdots$ & No \\
$99: 1$ & $\mathrm{DC}_{8,9} \mathrm{PC} / 5 \mathrm{~K}(1)$ & DSPE-PEG5000 & No \\
$90: 10$ & $\mathrm{DC}_{8,9} \mathrm{PC} / 5 \mathrm{~K}(10)$ & $\cdots$ & No \\
$80: 20$ & $\mathrm{DC}_{8,9} \mathrm{PC} / 5 \mathrm{~K}(20)$ & DSPE-PEG1000 & Yo \\
$90: 10$ & $\mathrm{DC}_{8,9} \mathrm{PC} / 1 \mathrm{~K}(10)$ & DSPE-PEG2000 & Yes \\
$90: 10$ & $\mathrm{DC}_{8,9} \mathrm{PC} / 2 \mathrm{~K}(10) / \mathrm{HPPH}$ & DSPE-PEG2000 & Yes \\
$80: 20$ & $\mathrm{DC}_{8,9} \mathrm{PC} / 2 \mathrm{~K}(20) / \mathrm{HPPH}$ & DSPE-PEG5000 & Yes \\
$90: 10$ & $\mathrm{DC}_{8,9} \mathrm{PC} / 5 \mathrm{~K}(10) / \mathrm{HPPH}$ & & \\
\hline
\end{tabular}

*The numbers in parentheses indicate the mol\% of PEGylated lipid in the liposomal formulations added 
scanned from 25 to $75^{\circ} \mathrm{C}$ at a heating rate of $10^{\circ} \mathrm{C} \mathrm{min}{ }^{-1}$ in an inert UHP nitrogen environment maintained at a flowrate of $40 \mathrm{~mL} \mathrm{~min}{ }^{-1}$. The results were duplicated for reproducibility.

\section{Results and discussion}

\section{Size and surface charge of the LNPs}

Figure 1 summarizes the average particle hydrodynamic diameters and corresponding polydispersity indices (PDI) of the LNPs with (a) and without (b) encapsulated HPPH enlisted in Table 1.

$\mathrm{DC}_{8,}{ }_{9} \mathrm{PC}$ lipids have reported to form larger tubular structures in aqueous solutions which is consistent with the large particle size of $1580 \pm 30 \mathrm{~nm}$ with a PDI $>1[29,47]$. In the presence of PEGylated DSPE, the measured diameter of the resultant $\mathrm{DC}_{8,9} \mathrm{PC}$ lipids LNPs dramatically reduced from $1580 \mathrm{~nm}$ to the range of 50 to $110 \mathrm{~nm}$ with lower PDIs between 0.2 and 0.45 . This $93-96 \%$ reduction is size and induced uniformity in the particle diameters is attributed to the inclusion of DSPE-PEG in the tubular $\mathrm{DC}_{8,9} \mathrm{PC}$ bilayer. Owing to its large hydrophilic head group, DSPE-PEG, induces curvature in the tubular morphology at smaller concentrations. Upon increasing the concentration of DSPE-PEG, the curvature of outer layer of the tubular bilayer changes further resulting in a favorable vesicular transformation [61, 77-79]. It is also observed that the formulations with $10 \mathrm{~mol} \%$ DSPE-PEG in the case of $1 \mathrm{~K}$ and
$5 \mathrm{~K}$ DSPE- PEG, and $10 \mathrm{~mol} \%$ and $20 \mathrm{~mol} \%$ DSPE-PEG2K are found to be uniformly monodispersed and within the acceptable nano-carrier size range of 70-200 nm and, therefore [80, 81], used to encapsulate hydrophobic drug HPPH. Figure $1 \mathrm{~b}$ represents the change in hydrodynamic diameter and PDI of the selected formulations. The encapsulation of hydrophobic HPPH was seen to further reduce the average diameter of the LNPs representing an overall 5-15\% in size reduction at lower PDIs of 0.2. This is attributed to the tighter packing of the lipids induced by the presence of HPPH which arises from intermolecular bond formations between the donor hydrogen electrons in the porphyrin ring of HPPH molecules and acceptor oxygen atoms on the glycerol moiety in the lipids. An in-depth mechanistic study of the influence of varying concentration of HPPH in the lipid bilayer is warranted and being investigated. Previous studies indicate that higher concentrations of HPPH molecules in the bilayer result in tighter lipid packing and consequently increase the stability of the lipid bilayer $[61,77,82,83]$

\section{Thermal analysis of the LNPs}

The influence of concentrations and molecular mass of PEG polymers, and the presence of hydrophobic HPPH on the lipid segregation that leads to phase separation and domain formation in the lipid bilayer was observed by DSC. Correlations between theoretically calculated thermodynamic parameters and stability of the formulations were based on analysis of the melting curve of the lipids. The melting temperatures of pure $\mathrm{DC}_{8,9} \mathrm{PC}$ are $45^{\circ} \mathrm{C}$, pure DSPE-PEG (a)

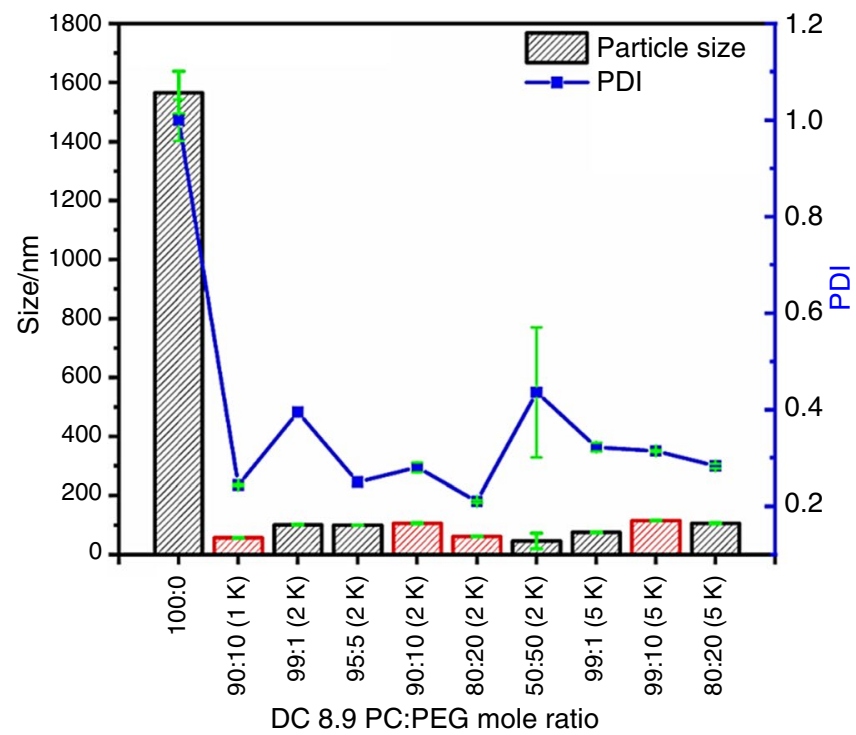

(b)

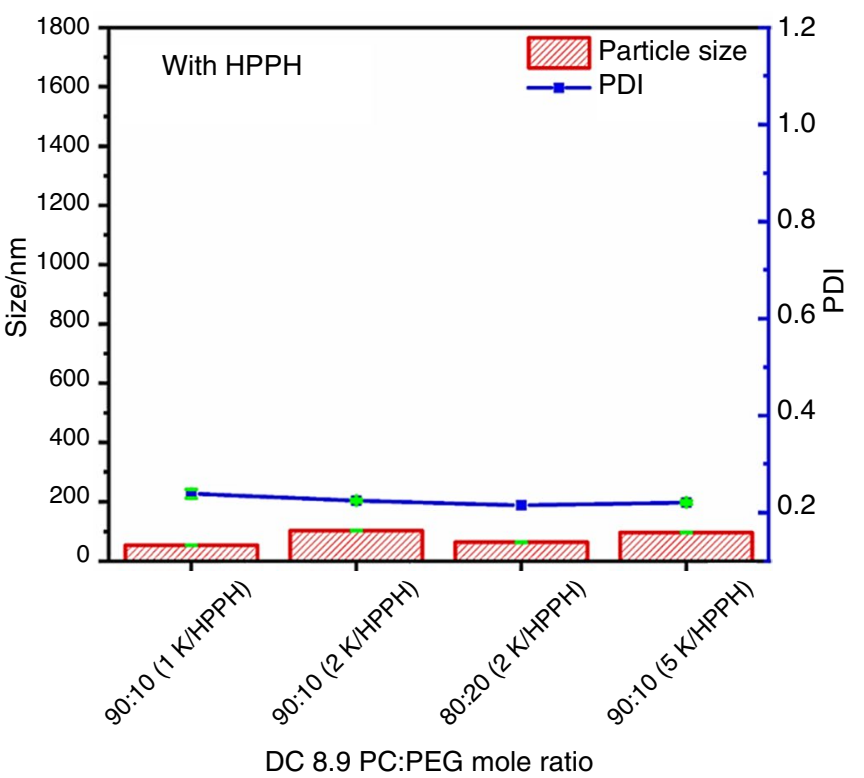

Fig. 1 Size and PDI of a LNP formulations prepared without HPPH. b LNP formulations prepared in the presence of HPPH (20:1, lipid: HPPH) 
dispersions (irrespective of molecular weight) was $52{ }^{\circ} \mathrm{C}$ and porphyrin photosensitizers degrade around $200-300^{\circ} \mathrm{C}$ [84-86].

\section{Effect of lower molecular weight DSPE-PEG (1000 and 2000) on phase transitions of DC ${ }_{8,9}$ PC/PEG- DSPE LNPs without HPPH}

Figure 2a shows a distinct shift of the main melting transiting peak of $\mathrm{DC}_{8,9} \mathrm{PC}$ toward lower temperature with increased concentration of PEG-2000 DSPE lipids. Pure $\mathrm{DC}_{8,9} \mathrm{PC}$ liposomes show a melting peak $\left(T_{\mathrm{m}}\right)$ at $45^{\circ} \mathrm{C}$ with a small pretransition peak around $38{ }^{\circ} \mathrm{C}$ (shown in black) which is reported to occur due to the melting of the characteristic tubular microstructures of $\mathrm{DC}_{8,9} \mathrm{PC}$ that are formed at lower temperatures [87]. These larger microtubular structure were confirmed to have an average diameter of $1580 \pm 30 \mathrm{~nm}$ in Fig. 1a. In the presence of 1 mol\% of DSPE-PEG2000 lipid (red), no significant change was observed except a slight broadening of the melting peak compared to pure $\mathrm{DC}_{8,9}$ PC. However, at 5 mol\% DSPE-PEG2000, a tall and sharp melting peak owing to larger heat capacity was observed at $43.97 \pm 0.92{ }^{\circ} \mathrm{C}$ with disappearance of the pretransition peak. Upon further increasing the DSPE-PEG2000 concentration to $10 \mathrm{~mol} \%$, the main transition peak broadened and shifted left to $42.87 \pm 0.56{ }^{\circ} \mathrm{C}$. With subsequent addition of DSPE-PEG2000 at 20 and $50 \mathrm{~mol} \%$, the main transition peak began to diminish while shifting toward lower temperature. The DSC curves for the corresponding formulations in the week 4 in Fig. 2b showed similar trends, however, with reduced prominence of the melting peak. We also observed that at the end of 4 weeks (Fig. 2b.), except for formulations
2 K (5) and 2 K (10) while all the other LNPs were devoid of significant enthalpies of transition. As indicated earlier, the broadening of the melting peak, phase separated, melting domain formation and any other change observed in the shape of the melting peak correlates to the changes in the lipid bilayer due to surface binding or the presence of moieties in the bilayer region. Herein, theoretical quantification of the changes in melting peak due to presence of therapeutic foreign molecules such as HPPH in this work and the effect of their cooperativity on lipid bilayer is computed as enthalpy and the half-width of melting peak as summarized in Table 2. The thermodynamic properties associated with the melting peaks observed in Fig. 1a, b are also enlisted in Table 2.

Addition of DSPE-PEG2000 lipids to $\mathrm{DC}_{8,}{ }_{9} \mathrm{PC}$ in the examined range from $1 \mathrm{~mol} \%$ to $50 \mathrm{~mol} \%$ showed a decrease in the transition temperature and altered the associated enthalpy of transition of $\mathrm{DC}_{8,9} \mathrm{PC}$ bilayer. In week four (Fig. 2b), LNPs with DPSE-PEG $2 \mathrm{~K}$ (5) or at $5 \mathrm{~mol} \%$ demonstrated a significant decrease of $66 \%$ in enthalpy with broadened $T_{\mathrm{m}}$ peak and a transition shift to $42.96 \pm 0.69{ }^{\circ} \mathrm{C}$ from $45{ }^{\circ} \mathrm{C}$. Similarly, $2 \mathrm{~K}$ (10) or $10 \mathrm{~mol} \%$ exhibited a $61 \%$ decrease in enthalpy with negligible change in $T_{\mathrm{m}}$. This decrease in enthalpy after four weeks is attributed to the entanglement of the PEG head groups which leads to steric exclusion and subsequent dehydration of the lipid bilayer. This results in possible disruption of bilayer surface observed as broadened melting peak [88, 89].

The change in enthalpy is also attributed to lateral separation of constituent $\mathrm{DC}_{8,9} \mathrm{PC}$ bilayer lipids induced by the presence of DSPE-PEG lipids. Lateral separation, a characteristic of heterogeneity of lipids bilayer [90, 91], was (a)

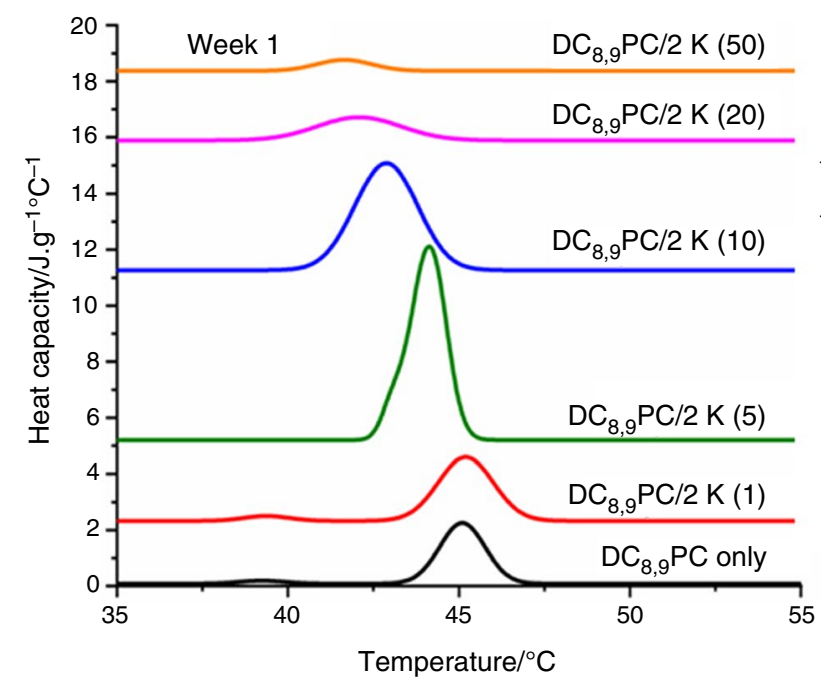

(b)

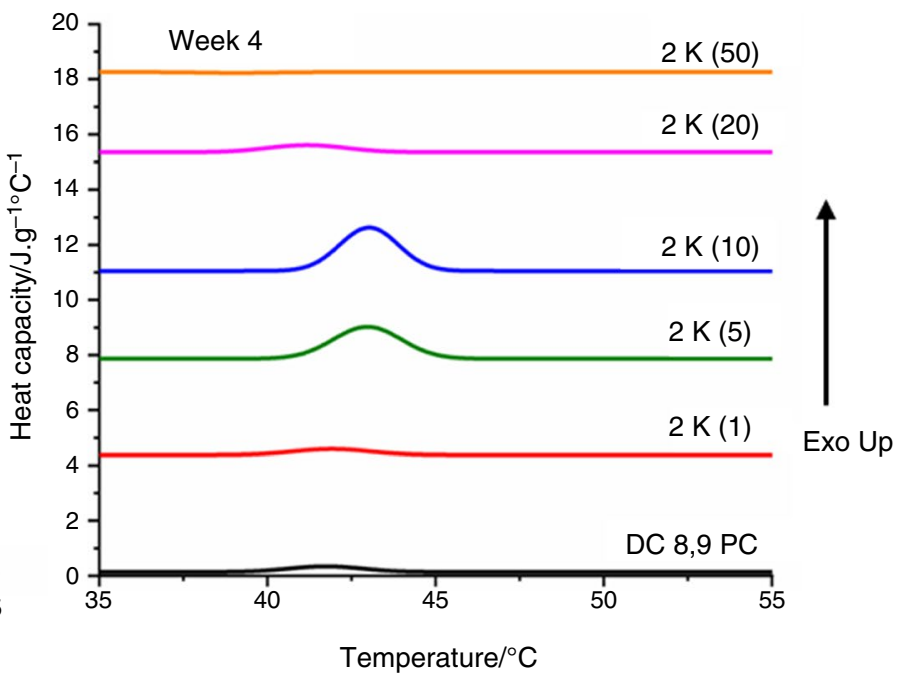

Fig. 2 DSC curves of $\mathrm{DC}_{8,9}$ PC/DSPE-PEG 2000 LNPs with varying PEG concentrations recorded in a) week 1 and b) week 4 
Table 2 Calculated thermodynamic parameters based on melting peaks presented in Fig. 2

\begin{tabular}{|c|c|c|c|c|c|c|}
\hline \multirow[t]{2}{*}{ LNP formulation } & \multicolumn{3}{|l|}{ Week 1} & \multicolumn{3}{|l|}{ Week 4} \\
\hline & $\begin{array}{l}\text { Transition tem- } \\
\text { perature }{ }^{\circ} \mathrm{C} / T_{\mathrm{m}}\end{array}$ & $\begin{array}{l}\text { Enthalpy of } \\
\text { transition } / \mathrm{J}^{-g^{-1}}\end{array}$ & $\begin{array}{l}\text { Half Width of } \\
\text { Transition } / \Delta \mathrm{T}_{1 / 2}\end{array}$ & Transition temperature ${ }^{\circ} \mathrm{C} / T_{\mathrm{m}}$ & $\begin{array}{l}\text { Enthalpy of } \\
\text { transition/J.g }\end{array}$ & $\begin{array}{l}\text { Half Width of } \\
\text { Transition } / \Delta \mathrm{T}_{1 / 2}\end{array}$ \\
\hline $\mathrm{DC}_{8,9} \mathrm{PC}$ & $45.09 \pm 0.23$ & $3.60 \pm 0.35$ & 1.67 & $41.67 \pm 0.18$ & $2.05 \pm 0.75$ & 2.4 \\
\hline $1 \mathrm{~K}(10)$ & $42.42 \pm 0.75$ & $1.18 \pm 0.75$ & 2.8 & $42.66 \pm 0.26$ & $0.81 \pm 0.36$ & 2.1 \\
\hline $2 \mathrm{~K}(1)$ & $45.19 \pm 0.45$ & $4.55 \pm 0.28$ & 4.02 & $41.9 \pm 0.45$ & $0.626 \pm 0.20$ & 2.89 \\
\hline $2 \mathrm{~K}(5)$ & $43.97 \pm 0.92$ & $8.54 \pm 0.32$ & 1.37 & $42.96 \pm 0.69$ & $2.9 \pm 0.28$ & 2.28 \\
\hline $2 \mathrm{~K}(10)$ & $42.87 \pm 0.56$ & $8.66 \pm 0.77$ & 2.03 & $43.02 \pm 0.48$ & $3.4 \pm 0.25$ & 2.02 \\
\hline $2 \mathrm{~K}(20)$ & $42.04 \pm 0.78$ & $2.50 \pm 0.87$ & 2.5 & $41.17 \pm 0.27$ & $0.74 \pm 0.56$ & 2.94 \\
\hline $2 \mathrm{~K}(50)$ & $41.66 \pm 0.98$ & $0.80 \pm 0.39$ & 1.65 & No peak observed & & \\
\hline $5 \mathrm{~K}(1)$ & $42.06 \pm 0.34$ & $3.33 \pm 0.55$ & 1.92 & $44.11 \pm 0.78$ & $1.69 \pm 0.49$ & 1.3 \\
\hline $5 \mathrm{~K}(10)$ & $42.06 \pm 0.20$ & $6.08 \pm 0.20$ & 1.99 & $42.92 \pm 0.65$ & $1.24 \pm 0.86$ & 1.93 \\
\hline $5 \mathrm{~K}(20)$ & $43.17 \pm 0.18$ & $0.49 \pm 0.12$ & 4.76 & $42.79 \pm 0.42$ & $0.627 \pm 0.50$ & 2.18 \\
\hline
\end{tabular}

predominant due to the presence of zwitterionic PC and $\mathrm{PE}$ and polymeric PEG chain. The intermolecular acyl tails of these lipids as well as the presence of dienes in the tail chain further the heterogeneity of the LNP carriers. Since the DSC studies were performed under constant pressure $(P)$ and volume $(V)$ condition, and according to the first law of thermodynamics,

$\Delta H_{(\text {Enthalpy })}=\Delta U_{(\text {kinetic }+ \text { potential energy })}+\Delta(P V)$

The calculated enthalpy is the internal energy or the sum of translational, vibrational, and rotational kinetic energies; and the potential energy arising from intermolecular and intramolecular interactions against the van der Waals forces of hydrocarbon chains in the $\mathrm{DC}_{8,9} \mathrm{PC}, \mathrm{DSPE}$ and PEG molecules similar to the ones reported in our previous work [1, 43, 92]. The fluidity of lipids is affected by temperature specifically, in their melting temperature region which results in change in their van der Waals force and thus impacting the overall enthalpy of the system. It is implied that various constituent lipids of the reported LNPs result undergo molecular interactions and perturbations causing lateral phase separation which is indicated by the broadening of the transition peaks. Since the pressure and volume were constant, $\Delta(P V)=0$.

The pronounced shift of the melting peak of $\mathrm{DC}_{8,9} \mathrm{PC}$ toward lower temperature with increasing mole fraction of DSPE-PEG is attributed to several reasons as follows: The presence of intercalated PEG in their amorphous state potentially disrupts the hydrogen bonding between the adjacent PC head groups, thereby destroying the structural arrangement of the head groups. Since the melting transition temperature is affected by the orientation of the head groups, the melting point is decreased as the concentration of DSPEPEG increases [93, 94]. The presence of salt ions in the HBS buffer presumably induces an osmotic stress $\left(\Delta G_{\mathrm{OS}}\right)$ in the lipid bilayer. The osmotic stress affects the curvature of the bilayer resulting in dramatic decrease of average diameters of the LNPs as observed in Fig. 1 [95].

The shift in temperature associated with gel to crystalline phase $\Delta T_{\mathrm{t}}^{\text {hyd }}$ is given by

$\Delta T_{\mathrm{t}}^{\mathrm{hyd}}=\Delta T_{\mathrm{t} \infty}^{\mathrm{hyd}} \tanh \left(\frac{\eta_{\mathrm{w}} V_{\mathrm{w}}}{\xi S_{\mathrm{L}}}\right)$

where $\eta_{\mathrm{w}} V_{\mathrm{w}}$ is the number of bound water molecules to the lipid bilayer, $V_{\mathrm{w}}$ the volume of one water molecule, $\xi$ the correlation length of water polarization.

It is been reported that some lipid molecules adopt a $P_{\beta}$ ' ripple phase from the crystalline $L_{\beta}$ phase in order to maintain the shape of the bilayer and to balance the water content in the bilayer. The resultant mixture of rippled tails and liquid disordered phase further reduce the phase transition temperature. The rippled phase has a lower degree of fluidity and resembles the gel phase which occurs at lower temperatures [96, 97].

Upon reduction of molecular weight of PEG from 2000 to 1000 in LNPs formulation at sample concentration of $10 \mathrm{~mol}$ $\%$, DSC studies in Fig. 2a indicated no change in the melting temperature; however, the enthalpy showed a decrease by $45 \%$ enlisted in Table 2 . This increment in enthalpy is the consequence of van der Waals forces. The van der Waals forces between the shorter PEG chains of lipids heads weaken with time resulting in an disrupted bilayer[2].

\section{Effect of higher molecular weight DSPE-PEG (5000) on Phase Transitions of DC ${ }_{8,9}$ PC/PEG- DSPE LNPs without HPPH}

Contrasting effects of high molecular weight PEG associated with DSPE lipid in $\mathrm{DC}_{8,9} \mathrm{PC}$ matrix invested at 1,10 and $20 \mathrm{~mol} \%$ ratios of PEG5000 using DSC is presented in 
(a)

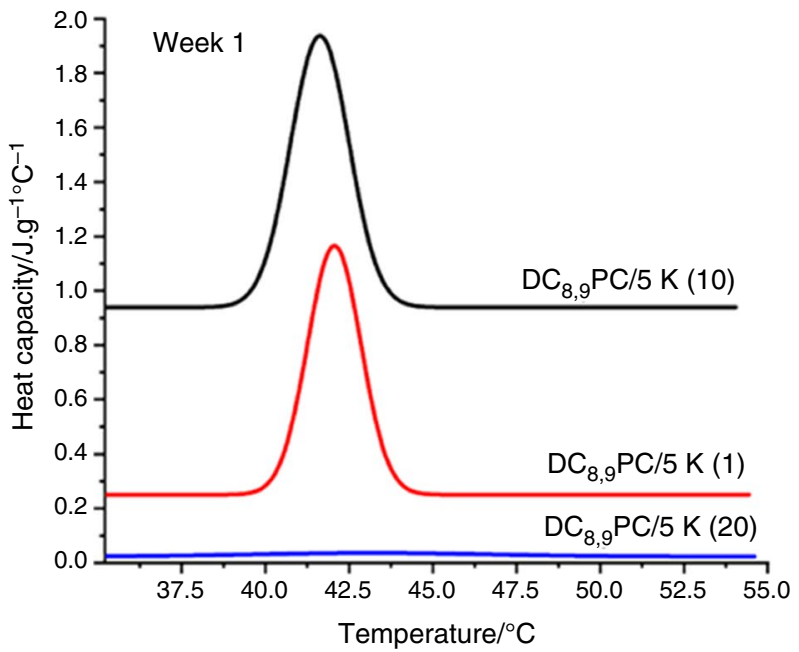

(b)

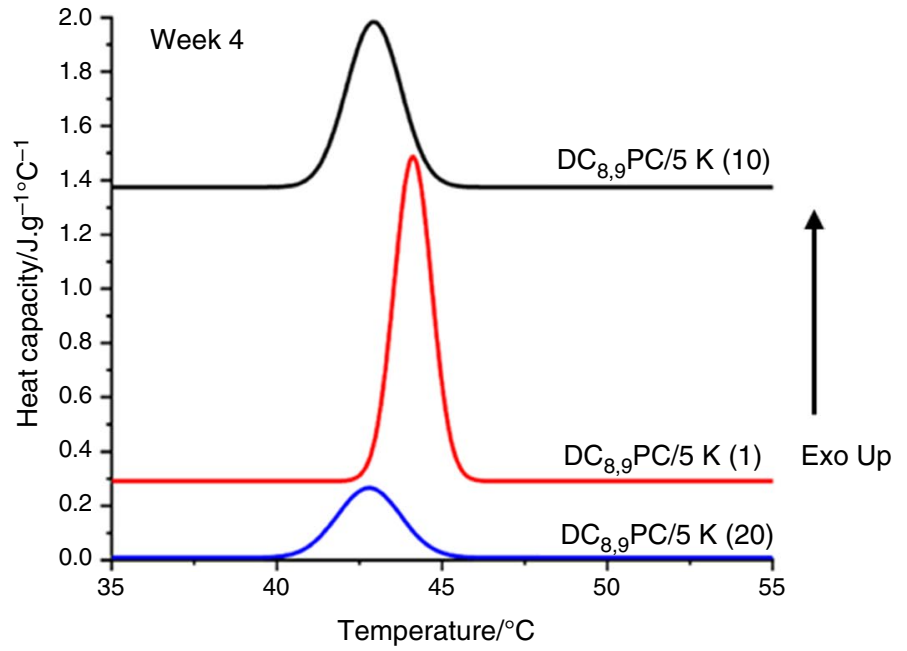

Fig. 3 DSC curves of binary mixtures of $\mathrm{DC}_{8,9}$ PC/DSPE-PEG 5000 LNP's varying in PEG concentrations

Fig. 3. As seen from DSC curves, LNPs with higher concentrations $>20 \mathrm{~mol} \%$ resulted in the disappearance of the melting peak due to lateral phase separation which is also supported by previous report [47].

In the presence of $1 \mathrm{~mol} \%$ of DSPE-PEG5000 lipids, the $T_{\mathrm{m}}$ was found to be $42.06 \pm 0.34{ }^{\circ} \mathrm{C}$ at the end of week 1 , which increased to $44.11 \pm 0.78{ }^{\circ} \mathrm{C}$ and accompanied by a $23 \%$ decrease in enthalpy shown as narrowing of the melting peak.

At $10 \mathrm{~mol} \%$ PEG-5000, a slight shift in $T_{\mathrm{m}}$ to $42.92{ }^{\circ} \mathrm{C}$ is accompanied by a significant reduction enthalpy by $79 \%$. Slight increase in transition temperature with a significant decrease in enthalpy at the end of four weeks in samples containing DSPE-PEG5000 is attributed to the increased mobility of PEG-5000 by virtue of the increased chain length that results in ancillary inter and intra molecular interactions, increasing the internal energy within the bilayer regions of LNPs. However, at $20 \mathrm{~mol} \%$, a very broad peak

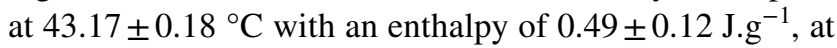
the end of week 1 was observed. Subsequently, at week 4 , there was a shift of $T_{\mathrm{m}}$ to $42.79 \pm 0.42{ }^{\circ} \mathrm{C}$, with an increase in $28 \%$ enthalpy. The longer the PEG chain length in LNP bilayer, larger are the van der Waals forces the between the PEG molecules in the lipid head group and outer leaflet regions, that furthers higher transition temperatures $[98,99]$. The overall reduction in enthalpy in the DSPE-PEG5000 formulations is congruent with formulations containing 10 and $20 \mathrm{~mol} \%$ DSPE-PEG 2000.

Consequently, differential scanning calorimetry studies and thermodynamic correlations provide indications of thermal stability of the LNPs, and resultant molecular perturbations caused integration of DSPE-PEG lipids into the $\mathrm{DC}_{8,9}$ lipid matrix. Additionally, the size analysis supports the physical or steric stability by demonstrating the homogenous nature of the LNP formulations. Based on the DSC and DLS studies, LNPs comprising of $10 \mathrm{~mol} \%$ DSPE-PEG-1000, 2000 and 5000 lipids, and $20 \mathrm{~mol} \%$ DSPE-PEG2000 were chosen for encapsulation of HPPH.

\section{Effect of incorporation of $\mathrm{HPPH}$ on the $\mathrm{DC}_{8,9} \mathrm{PC} /$ DSPE-PEG LNPs}

The HPPH-encapsulated LNPs demonstrated monodispersity evidenced by a measured of $\mathrm{PDI} \leq 0.2$ similar to their unencapsulated LNPs equivalents. However, the presence of HPPH altered the bilayer packing resulting in reduction of LNPs diameter between 5-15\% corresponding to the ratio and molecular weight of DSPE-PEG. This variation in LNP diameter is a characteristic lipid packing modification due to the presence of HPPH, which further alters the fluidity of the lipid bilayer that is emulated on DSC curves in Fig. 4.

Figure 4 represents the stability of formulations containing 10 and $20 \mathrm{~mol} \%$ of DSPE-PEG LNPs of varying PEG chain lengths 1000, 2000, 5000 in the presence and absence of HPPH in week 1 and week 4, respectively. When compared to unencapsulated LNPs $2 \mathrm{~K}$ (10), during week 1, on incorporating $\mathrm{HPPH}$, there is no significant change in the enthalpy of transition and the $T_{\mathrm{m}}$ is shifted to a slightly lower temperature $\left(T_{\mathrm{m}}=42.06 \pm 0.10^{\circ} \mathrm{C}\right)$. In the week $4,2 \mathrm{~K}(10) /$ $\mathrm{HPPH}$, had further shifter to a lower $T_{\mathrm{m}}$ of $41.67 \pm 0.48^{\circ} \mathrm{C}$

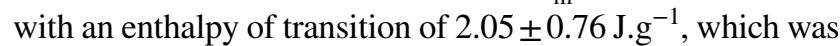
$40 \%$ decrease in enthalpy as compared to the plain sample in Fig. 4b. 
(a)

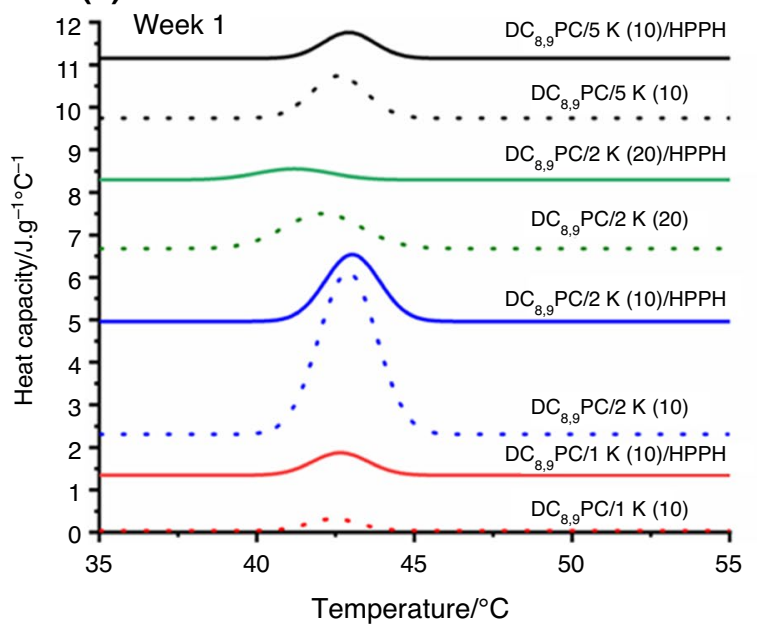

(b)

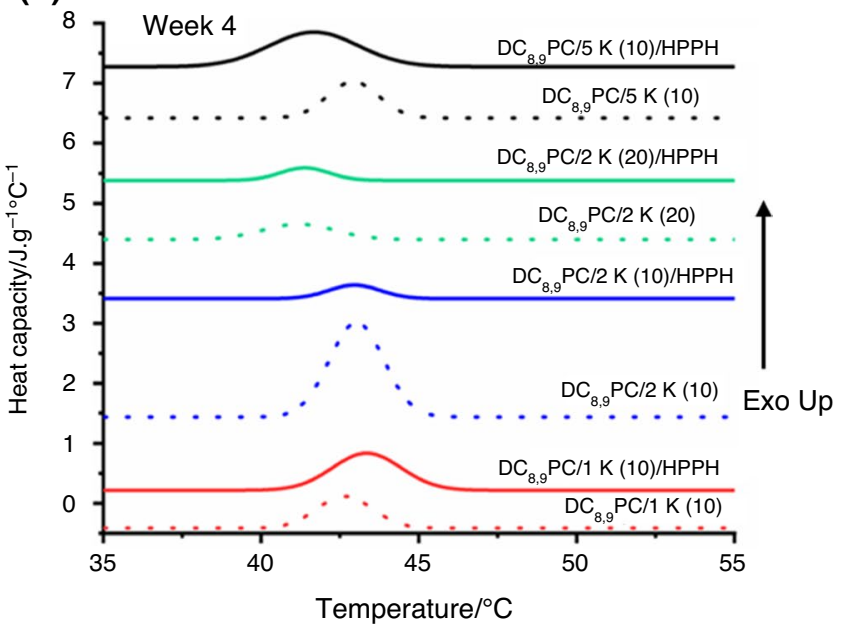

Fig. 4 DSC curves of $\mathrm{DC}_{8,9}$ PC/DSPE-PEG formulation in the absence and presence of encapsulated HPPH

Table 3 Comparison of melting temperature and enthalpies of LNP with and without encapsulated HPPH from week 1 to week 4

\begin{tabular}{llllll}
\hline Lipid formulation & \multicolumn{2}{l}{ Week 1} & & Week 4 & \\
\cline { 2 - 3 } \cline { 5 - 6 } & $\begin{array}{l}\text { Transition tempera- } \\
\text { ture }{ }^{\circ} \mathrm{C} / T_{\mathrm{m}}\end{array}$ & $\begin{array}{l}\text { Enthalpy of } \\
\text { transition } / \mathrm{J} . \mathrm{g}^{-1}\end{array}$ & & $\begin{array}{l}\text { Transition tempera- } \\
\text { ture }{ }^{\circ} \mathrm{C} / T_{\mathrm{m}}\end{array}$ & $\begin{array}{l}\text { Enthalpy of } \\
\text { transition/J. } \\
\mathrm{g}^{-1}\end{array}$ \\
\hline $1 \mathrm{~K}(10)$ & $42.42 \pm 0.45$ & $0.81 \pm 0.65$ & & $42.66 \pm 0.15$ & $1.18 \pm 0.65$ \\
$1 \mathrm{~K}(10) / \mathrm{HPPH}$ & $42.32 \pm 0.32$ & $6.79 \pm 0.70$ & & $42.97 \pm 0.55$ & $0.468 \pm 0.49$ \\
$2 \mathrm{~K}(10)$ & $42.87 \pm 0.85$ & $8.66 \pm 0.38$ & & $43.04 \pm 0.08$ & $3.4 \pm 0.13$ \\
$2 \mathrm{~K}(10) / \mathrm{HPPH}$ & $42.06 \pm 0.10$ & $8.08 \pm 0.95$ & & $41.67 \pm 0.48$ & $2.05 \pm 0.76$ \\
$2 \mathrm{~K}(20)$ & $42.04 \pm 0.16$ & $2.5 \pm 0.55$ & & $41.17 \pm 0.09$ & $0.74 \pm 0.11$ \\
$2 \mathrm{~K}(10) / \mathrm{HPPH}$ & $41.06 \pm 0.35$ & $0.38 \pm 0.73$ & & $41.37 \pm 0.20$ & $0.21 \pm 0.54$ \\
$5 \mathrm{~K}(10)$ & $42.02 \pm 0.89$ & $6.08 \pm 0.20$ & & $44.11 \pm 0.04$ & $1.69 \pm 0.14$ \\
$5 \mathrm{~K}(10) / \mathrm{HPPH}$ & $42.45 \pm 0.40$ & $0.89 \pm 0.35$ & & $42.92 \pm 0.92$ & $1.24 \pm 0.29$ \\
\hline
\end{tabular}

Similar trends of lower $T_{\mathrm{m}}$ and enthalpy have been observed in formulations with HPPH has been observed with $1 \mathrm{~K}(10), 2 \mathrm{~K}(20)$ and $5 \mathrm{~K}(10)$ as tabulated in Table 3.

It is observed that all the investigated LNPs encapsulating HPPH demonstrated lower enthalpies compared to their unencapsulated equivalents except the LNPs constituting 10 mol\% PEG-5000. HPPH being hydrophobic accumulates in the tail region of the bilayer. Structurally, the donor hydrogen electrons in the porphyrin ring of $\mathrm{HPPH}$ has donor interacts with the acceptor oxygen electrons in the glycerol moieties of the lipids and form hydrogen bonds[82, 83]. The presence of HPPH in the hydrophobic alkyl tails gives rise to previously discussed van der Waals forces that enables increased tightness of lipid packing and modification of the overall membrane curvature. The formation of these bonds limits the fluidity of the lipid molecules, thereby reducing the internal energy of the lipid bilayer in the presence of HPPH molecules. This change in internal energy is quantified by computing the enthalpy of transition summarized in Table 3.

The significant increase in enthalpy of LNPs consisting of 10 mol\% of PEG-5000 is assumed due to the strong van der Waals force arising from the intercalation of longer DSPE5000 PEG chains, which counteracts the presence of HPPH. This results in an increased curvature of the LNP rendering them unsuitable for drug delivery applications.

It is inferred from the size and DSC studies that out of four of the formulations that encapsulated HPPH, $2 \mathrm{~K}(10) /$ HPPH is the optimum formulation because size of the carrier $(104 \mathrm{~nm})$ is well within the standard size range of the nano-carriers (70-200 $\mathrm{nm}$ ) used in drug delivery.

The reduction of enthalpy in the presence of $\mathrm{HPPH,}$ which corresponds to phase separation of formulation, at the end of week 4 is not significant compared to $2 \mathrm{~K}$ (10) in Week 4. This is presumed due to the optimum van der Waals force that counteracts the presence of HPPH in the hydrophobic tail region and is responsible for the stability 
Fig. 5 Schematic representation of bond formations between HPPH with various moieties on lipid headgroup and tails

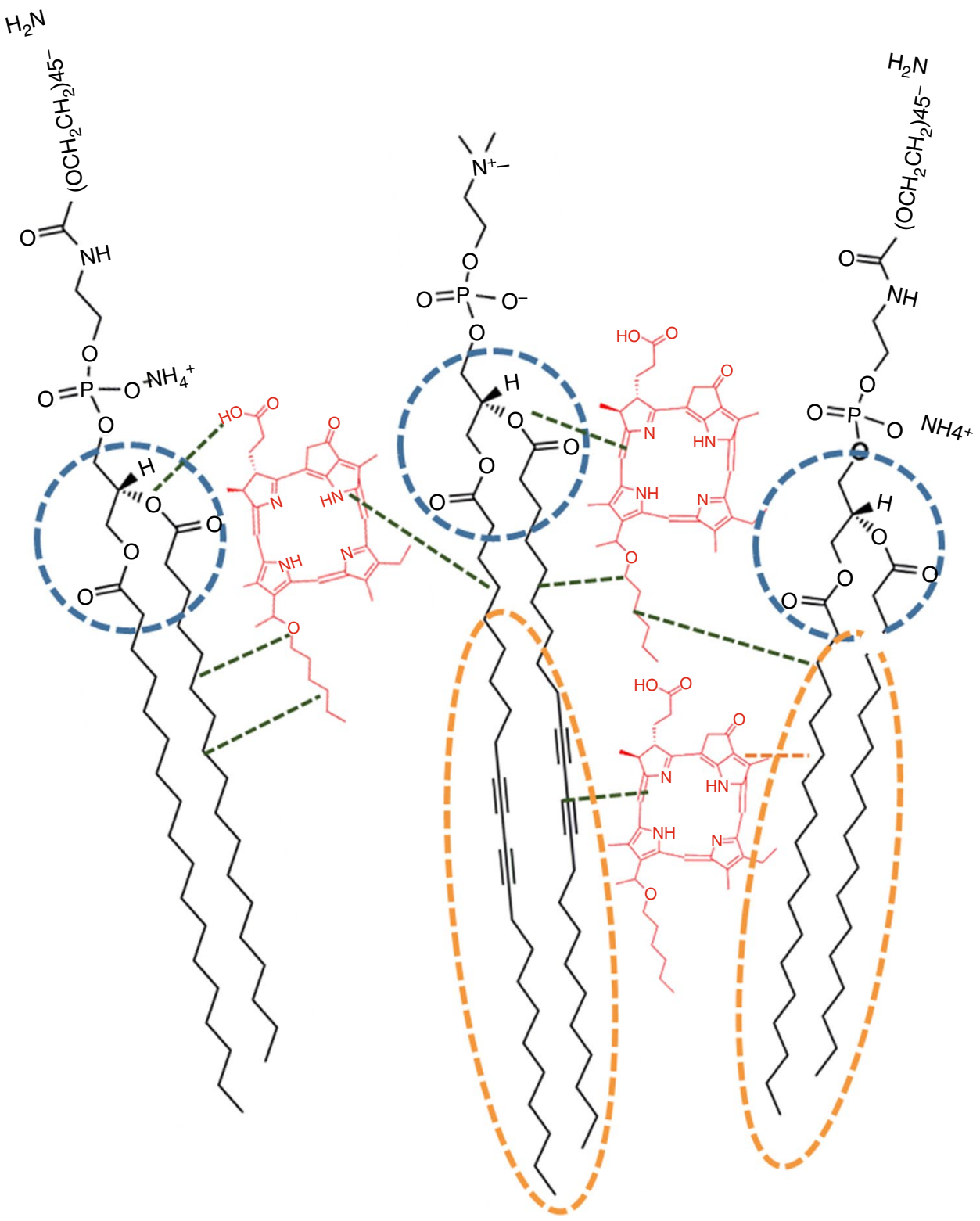

of the formulation as shown in Fig. 5. This work facilitates the significance of thermal stability studies in development of lipid-based carriers and vaccines [100-102] which are susceptible to temperatures[103-107]. This model study can potentially be applied to design thermally stable lipid-based vaccines including the anticipated COVID-19 vaccine for their prolonged stability during their storage, transportation, and distribution.

\section{Conclusions}

In this work, we demonstrate the thermal and steric stability of HPPH-encapsulated lipid-based carriers imparted by PEGylated lipids. A systematic investigation was conducted using DSC on the effects of varying molecular mass and concentrations of PEG polymers in the photopolymerizable lipid $\mathrm{DC}_{8,9} \mathrm{PC}$ lipid bilayer matrix. Intuitively, the lower concentration of PEG-lipids demonstrated higher stability to reduced phase separation arising from heterogeneity in the lipid bilayer. It was found that both smaller and larger PEG chains- $1 \mathrm{~K}$ and $5 \mathrm{~K}$ thermally unstable formulations; however, $\mathrm{PEG}-2 \mathrm{~K}$ resulted in stable formulations due to their optimum size that results in van der Waal interactions with lipid groups. It was observed that the encapsulation of HPPH enhanced the thermal stability via formation of hydrogen bonds with lipid moieties that increased the packing order of the bilayer comprising of PEG-2 K molecules. These formulations have previously showed efficacy in vivo studies. It is concluded that 
the encapsulation of therapeutics in lipid formulations can alter their overall thermal stability. It is postulated that the research methodologies and findings presented in this work can also be applied to predict the stability of lipid-based vaccines during their storage, transport, and distribution.

\section{References}

1. Kalyanram P, Ma H, Marshall S, Goudreau C, Cartaya A, Zimmerman $\mathrm{T}$, et al. Interaction of amphiphilic coumarin with DPPC/DPPS lipid bilayer: effects of concentration and alkyl tail length. Phys Chem Chem Phys. 2020;22:15197-207.

2. Gupta A, Kalyanram P, Stadler I. Interaction of riboflavin5-phosphate with liposome bilayers. J Nanotoxicology Nanomedicine. 2019;3:49-59.

3. Preiss MR, Gupta A, Bothun G. Liposome-Nanoparticle Assemblies, Bionanotechnology: Biological self-assembly and its applications. Norwich, UK: Horizon Scientific Press; 2013.

4. Gupta A, Gupta R, Kurwardkar S. Liposome-encapsulated antimicrobial peptides: potential infectious diseases therapy. Handb Res Divers Appl Nanotechnol Biomed Chem Eng. IGI Global, 2014;301-32.

5. Gupta A, Mandal D, Ahmadibeni Y, Parang K, Bothun G. Hydrophobicity drives the cellular uptake of short cationic peptide ligands. Eur Biophys J. 2011;40:727-36.

6. Gupta A. Investigation of interaction of cationic amphiphiles with model membranes and their application in drug delivery, University of Rhode Island, 2011.

7. Kalyanram P, Hussein N, Tiwari A, Gupta A. Insights on the thermal and physical stability of the modified polymerizable liposomes for improved photoactivity. Int J Lipids. 2020;1:11-24.

8. Kalyanram P, Puri A, Gupta A. Understanding the stealth properties of PEGylated lipids: a mini-review. Int J Lipids. 2020;1:1-20.

9. Kalyanram P. Interactions of photosensitizers with model membranes and their applications in photodynamic therapy. Rochester Institute of Technology, 2020.

10. Akbarzadeh A, Rezaei-Sadabady R, Davaran S, Joo SW, Zarghami N, Hanifehpour Y, et al. Liposome: classification, preparation, and applications. Nanoscale Res Lett. 2013;8:102.

11. Allen TM, Cullis PR. Liposomal drug delivery systems: from concept to clinical applications. Adv Drug Deliv Rev. 2013;36-48.

12. Çağdaş M, Sezer AD, Bucak S. Liposomes as potential drug carrier systems for drug delivery. Appl Nanotechnol Drug Deliv. InTech, 2014

13. Schwendener RA. Liposomes as vaccine delivery systems: a review of the recent advances. Ther Adv Vaccines 2014;159-82.

14. Miquel-Clopés A, Bentley EG, Stewart JP, Carding SR. Mucosal vaccines and technology. Clin Exp Immunol 2019; 205-14.

15. Henriksen-Lacey M, Korsholm KS, Andersen P, Perrie Y, Christensen D. Liposomal vaccine delivery systems. Expert Opin. Drug Deliv.2011; 505-19.

16. Lasic DD. On the thermodynamic stability of liposomes. J Colloid Interface Sci.1990;302-04.

17. Grit M, Crommelin DJA. Chemical stability of liposomes: implications for their physical stability. Chem Phys Lipids. 1993;64:3-18.

18. Dhruv HD. Controlling nonspecific adsorption of proteins at bio-interfaces controlling nonspecific adsorption of proteins at bio-interfaces for biosensor and biomedical applications for biosensor and biomedical applications. Utah State University; 2009

19. Ojogun VA. Effect of fluorination on partitioning behavior and bilayer self assembly. University of Kentucky, 2010.

20. Uchegbu IF, Cheng WP, Schätzlein AG, Lalatsa A. Fundamentals of pharmaceutical nanoscience. New York: Springer; 2013.

21. Ghanbarzadeh S, Valizadeh H, Zakeri-Milani P. The effects of lyophilization on the physico-chemical stability of sirolimus liposomes. Adv Pharm Bull. 2013;3:25-9.

22. Payton NM, Wempe MF, Xu Y, Anchordoquy TJ. Long-term storage of lyophilized liposomal formulations. J Pharm Sci. 2014;103:3869-78.

23. Crommelin DJA, Fransen GJ, Salemink PJM. Stability of liposomes on storage. Target drugs with synth system. Boston: Springer; 1986. p. 277-87.

24. Yavlovich A, Smith B, Gupta K, Blumenthal R, Puri A. Lightsensitive lipid-based nanoparticles for drug delivery: design principles and future considerations for biological applications. Mol Membr Biol. 2010;27:364-81.

25. Alvarez-Lorenzo C, Bromberg L, Concheiro A. Light-sensitive intelligent drug delivery systems. Photochem Photobiol. 2009;848-60.

26. Shum P, Kim JM, Thompson DH. Phototriggering of liposomal drug delivery systems. Adv Drug Deliv Rev. 2001;53:273-84.

27. Leung SJ, Romanowski M. Light-activated content release from liposomes. Theranostics. 2012;2:1020-36.

28. Qin G, Li Z, Xia R, Li F, O'Neill B, et al. Partially polymerized liposomes: stable against leakage yet capable of instantaneous release for remote controlled drug delivery. Nanotechnology. 2011;22:155605.

29. Rhodes DG, Blechner SL, Yager P, Schoen PE. Structure of polymerizable lipid bilayers. I-1,2-bis(10,12-tricosadiynoyl)sn-glycero-3-phosphocholine, a tubule-forming phosphatidylcholine. Chem Phys Lipids. 1988;49:39-47.

30. Puri A, Blumenthal RP, Joshi A, Tata DB, Viard M. U.S. Patent No. 10,117,942. Washington: US Patent and Trademark Office; 2018.

31. Takeuchi H, Kojima H, Yamamoto H, Kawashima Y. Polymer coating of liposomes with a modified polyvinyl alcohol and their systemic circulation and RES uptake in rats. J Control Release. 2000;68:195-205.

32. Mu X, Zhong Z. Preparation and properties of poly(vinyl alcohol)-stabilized liposomes. Int J Pharm. 2006;318:55-61.

33. Liu J, Boonkaew B, Arora J, Mandava SH, Maddox MM, Chava $\mathrm{S}$, et al. Comparison of sorafenib-loaded poly (Lactic/Glycolic) acid and dppc liposome nanoparticles in the in vitro treatment of renal cell carcinoma. J Pharm Sci. 2015;104:1187-96.

34. Verrecchia T, Spenlehauer G, Bazile DV, Murry-Brelier A, Archimbaud Y, Veillard M. Non-stealth (poly(lactic acid/ albumin)) and stealth (poly(lactic acid-polyethylene glycol)) nanoparticles as injectable drug carriers. J Control Release. 1995;36:49-61.

35. MartinFJ, Woodle MC, Redemann C, Yau-Young A. U.S. Patent No. 5,213,804. Washington: U.S. Patent and Trademark Office; 1993.

36. Woodle MC. Sterically stabilized liposome therapeutics. Adv Drug Deliv Rev. 1995;249-65.

37. Kostarelos K, Tadros TF, Luckham PF. Physical conjugation of (Tri-) block copolymers to liposomes toward the construction of sterically stabilized vesicle systems. Langmuir. 1999;15:369-76.

38. Silvander M. Steric stabilization of liposomes - a review. In: Nylander T, Lindman B, editors. Lipid and polymer-lipid systems. Progress in Colloid and Polymer Science. Berlin: Springer; 2002. p. 35-40.

39. Harris JM, Chess RB. Effect of pegylation on pharmaceuticals. Nat Rev Drug Discov. 2003;2:214-21. 
40. Treanor R, Pace MD. Microstructure, order and fluidity of 1,2-bis(tricosa-10,12-diynoyl) -sn-glycero-3-phosphocholine (DC8,9PC), a polymerizable lipid, by ESR and NMR. Biochim Biophys Acta Lipids Lipid Metab. 1990;1046:1-11.

41. Colantonio S, Simpson JT, Fisher RJ, Yavlovich A, Belanger JM, Puri A, et al. Quantitative analysis of phospholipids using nanostructured laser desorption ionization targets. Lipids. 2011;46:469-77.

42. Puri A. Phototriggerable liposomes: current research and future perspectives. Pharmaceutics. 2014;1-25.

43. Puri A, Jang H, Yavlovich A, Masood MA, Veenstra TD, Luna C, et al. Material properties of matrix lipids determine the conformation and intermolecular reactivity of diacetylenic phosphatidylcholine in the lipid bilayer. Langmuir. 2011;27:15120-8.

44. Yavlovich A, Singh A, Blumenthal R, Puri A. A novel class of photo-triggerable liposomes containing DPPC:DC 8,9PC as vehicles for delivery of doxorubcin to cells. Biochim Biophys Acta Biomembr. 2011;1808:117-26.

45. Yavlovich A, Singh A, Tarasov S, Capala J, Blumenthal R, Puri A. Design of liposomes containing photopolymerizable phospholipids for triggered release of contents. J Therm Anal Calorim. 2009;98:97-104.

46. Puri A. Phototriggerable liposomes: current research and future perspectives. Pharmaceutics. 2013;6:1-25.

47. Viard M, Reichard H, Shapiro BA, Durrani FA, Marko AJ, Watson RM, et al. Design and biological activity of novel stealth polymeric lipid nanoparticles for enhanced delivery of hydrophobic photodynamic therapy drugs. Nanomed Nanotechnol Biol Med. 2018;14:2295-305.

48. Sun G, Anderson MA, Gorospe EC, Leggett CL, Lutzke LS, Wong K, Song LM, et al. Synergistic effects of photodynamic therapy with HPPH and gemcitabine in pancreatic cancer cell lines. Lasers Surg Med. 2012;44:755-61.

49. Bellnier DA, Greco WR, Loewen GM, Nava H, Oseroff AR, Dougherty TJ. Clinical pharmacokinetics of the PDT photosensitizers porfimer sodium (Photofrin), 2-[1-Hexyloxyethyl]2-Devinyl Pyropheophorbide-a (Photochlor) and 5-ALA-Induced Protoporphyrin IX. Lasers Surg Med. 2006;38:439-44.

50. Bellnier DA, Greco WR, Loewen GM, Nava H, Oseroff AR, Pandey RK, et al. Population pharmacokinetics of the photodynamic therapy agent 2-[1-Hexyloxyethyl]-2-devinyl pyropheophorbide$\mathrm{a}$ in cancer patients. Cancer Res. 2003;63:1806-13.

51. Cullis PR, Hope MJ. Lipid nanoparticle systems for enabling gene therapies. Mol Ther. 2017;25:1467-75.

52. Jokerst J V., Lobovkina T, Zare RN, Gambhir SS. Nanoparticle PEGylation for imaging and therapy. Nanomedicine. 2011;715-28

53. Suk JS, Xu Q, Kim N, Hanes J, Ensign LM. PEGylation as a strategy for improving nanoparticle-based drug and gene delivery. Adv Drug Deliv Rev. 2016; 28-51.

54. Nag OK, Awasthi V. Surface engineering of liposomes for stealth behavior. Pharmaceutics. 2013;542-69.

55. Moghimi SM, Szebeni J. Stealth liposomes and long circulating nanoparticles: critical issues in pharmacokinetics, opsonization and protein-binding properties. Prog Lipid Res. 2003;463-78.

56. Immordino ML, Dosio F, Cattel L. Stealth liposomes: Review of the basic science, rationale, and clinical applications, existing and potential. Int J Nanomedicine. 2006;1:297-315.

57. Garbuzenko O, Barenholz Y, Priev A. Effect of grafted PEG on liposome size and on compressibility and packing of lipid bilayer. Chem Phys Lipids. 2005;135:117-29.

58. Silvander M, Hansson P, Edwards K. Liposomal surface potential and bilayer packing as affected by PEG-lipid inclusion. Langmuir. 2000;6:3696-702.
59. Kepczyński M, Nawalany K, Kumorek M, Kobierska A, Jachimska B, Nowakowska M. Which physical and structural factors of liposome carriers control their drug-loading efficiency? Chem Phys Lipids. 2008;155:7-15.

60. Stepniewski M, Pasenkiewicz-Gierula M, Rog T, Danne R, Orlowski A, Karttunen M, et al. Study of PEGylated lipid layers as a model for PEGylated liposome surfaces: Molecular dynamics simulation and langmuir monolayer studies. Langmuir. 2011;27:7788-98.

61. Tsuda S, Sakakura T, Fujii S, Suzuki H, Yomo T. Shape Transformations of Lipid Vesicles by Insertion of Bulky-Head Lipids. PLoS ONE. 2015;10:e0132963.

62. Sheth SR, Leckband D. Measurements of attractive forces between proteins and end-grafted poly(ethylene glycol) chains. Proc Natl Acad Sci. 1997;94:8399-404.

63. Drobek T, Spencer ND, Heuberger M. Compressing PEG brushes. Macromolecules. 2005;38:5254-9.

64. Feng C, Huang X. Polymer brushes: efficient synthesis and applications. Acc Chem Res. 2018;51:2314-23.

65. Bedu-Addo FK, Tang P, Xu Y, Huang L. Effects of polyethyleneglycol chain length and phospholipid acyl chain composition on the interaction of polyethyleneglycol-phospholipid conjugates with phospholipid: implications in liposomal drug delivery. Pharm Res. 1996;13:710-7.

66. Bartucci R, Pantusa M, Marsh D, Sportelli L. Interaction of human serum albumin with membranes containing polymergrafted lipids: Spin-label ESR studies in the mushroom and brush regimes. Biochim Biophys Acta - Biomembr. 2002;1564:237-42.

67. Biltonen RL, Lichtenberg D. The use of differential scanning calorimetry as a tool to characterize liposome preparations. Chem Phys Lipids. 1993;64:129-42.

68. Chiu M, Prenner E. Differential scanning calorimetry: an invaluable tool for a detailed thermodynamic characterization of macromolecules and their interactions. J Pharm Bioallied Sci. 2011;39-59.

69. Demetzos C. Differential scanning calorimetry (DSC): a tool to study the thermal behavior of lipid bilayers and liposomal stability. J Liposome Res. 2008;18:159-73.

70. Torchilin VP, Weissig V. Liposomes: a practical approach. Oxford: Oxford University Press; 2003.

71. Welti-Chanes J. Water stress in biological, chemical, Pharmaceutical and Food Systems. New York: Springer; 2015.

72. Almeida EDP, Costa AA, Serafini MR, Rossetti FC, Marchetti JM, Sarmento VHV, et al. Preparation and characterization of chloroaluminum phthalocyanine-loaded solid lipid nanoparticles by thermal analysis and powder X-ray diffraction techniques. J Therm Anal Calorim. 2012;108:191-6.

73. De Souza ALR, Andreani T, Nunes FM, Cassimiro DL, De Almeida AE, Ribeiro CA, et al. Loading of praziquantel in the crystal lattice of solid lipid nanoparticles: Studies by DSC and SAXS. J Therm Anal Calorim. 2012;108:353-60.

74. Kasian N, Vashchenko O, Budianska L, Brodskii R, Lisetski L. Cooperative domains in lipid membranes: size determination by calorimetry. J Therm Anal Calorim. 2019;136:795-801.

75. Catenacci L, Sorrenti M, Bruni G, Bonferoni MC. Characterization of silver sulfadiazine-loaded solid lipid nanoparticles by thermal analysis chitosan oleate salt as an amphiphilic polymer for the surface modification of poly-lactic-glycolic acid (PLGA) nanoparticles. Preliminary studies of mucoadhesion and cell interaction properties. J Therm Anal Calorim. 2013;111:2149-55.

76. Gupta A, Gupta R, Kurwadkar S. Liposome encapsulated antimicrobial peptides: potential infectious diseases therapy: Handbook of Research on Diverse Applications of Nanotechnology in 
Biomedicine, Chemistry and Engineering. IGI Global Publisher; 2014.

77. Khajeh A, Modarress H. The influence of cholesterol on interactions and dynamics of ibuprofen in a lipid bilayer. Biochim Biophys Acta - Biomembr. 2014;1838:2431-8.

78. Lombardo D, Calandra P, Barreca D, Magazù S, Kiselev MA. Soft interaction in liposome nanocarriers for therapeutic drug delivery. Nanomaterials. 2016;6:125.

79. Viitala L, Pajari S, Gentile L, Määttä J, Gubitosi M, Deska J, et al. Shape and Phase Transitions in a PEGylated. Phospholipid System. 2019;35:3999-4010.

80. Kamaly N, Xiao Z, Valencia PM, Radovic-Moreno AF, Farokhzad OC. Targeted polymeric therapeutic nanoparticles: design, development and clinical translation. Chem Soc Rev. 2012;2971-3010

81. Majedi FS, Hasani-Sadrabadi MM, Hojjati Emami S, Shokrgozar MA, Vandersarl JJ, Dashtimoghadam E, et al. Microfluidic assisted self-assembly of chitosan based nanoparticles as drug delivery agents. Lab Chip. 2013;13:204-7.

82. Carter KA, Shao S, Hoopes MI, Luo D, Ahsan B, Grigoryants VM, et al. Porphyrin-phospholipid liposomes permeabilized by near-infrared light. Nat Commun. 2014;5:1-11.

83. Dzieciuch M, Rissanen S, Szydłowska N, Bunker A, Kumorek M, Jamróz D, et al. Pegylated liposomes as carriers of hydrophobic porphyrins. J Phys Chem B. 2015;119:6646-57.

84. Sahib MN, Abdalwahed S, Abdulameer SA, Darwis Y, Peh KK, Tan YTF. Solubilization of beclomethasone dipropionate in sterically stabilized phospholipid nanomicelles (SSMs): physicochemical and in vitro evaluations. Drug Des Devel Ther. 2012;6:29-42.

85. Abdulla JMA, Tan YTF, Darwis Y. Rehydrated lyophilized rifampicin-loaded mPEG-DSPE formulations for nebulization. AAPS PharmSciTech. 2010;11:663-71.

86. Sah U, Sharma K, Chaudhri N, Sankar M, Gopinath P. Antimicrobial photodynamic therapy: single-walled carbon nanotube (SWCNT)-Porphyrin conjugate for visible light mediated inactivation of Staphylococcus aureus. Colloids Surf B Biointerfaces. 2018;162:108-17.

87. Georger JH, Singh A, Price RR, Schnur JM, Yager P, Schoen PE. Helical and tubular microstructures formed by polymerizable phosphatidylcholines. J Am Chem Soc. 1987;109:6169-75.

88. Priev A, Samuni AM, Tirosh O, Barenholz Y. The role of hydration in stabilization of liposomes: resistance to oxidative damage of PEG-grafted liposomes. In: Gregoriadis G, McCormack B, editors. Targeting of Drugs 6. NATO ASI Series (Series A: Life Sciences). 1998;147-167

89. Morandi MI, Sommer M, Kluzek M, Thalmann F, Schroder AP, Marques CM. DPPC bilayers in solutions of high sucrose content. Biophys J. 2018;114:2165-73.

90. Hashizaki K, Taguchi H, Itoh C, Sakai H, Abe M, Saito Y, et al. Effects of poly(ethylene glycol) (PEG) chain length of PEGlipid on the permeability of liposomal bilayer membranes. Chem Pharm Bull. 2003;51:815-20.

91. Hashizaki K, Itoh C, Sakai H, Yokoyama S, Taguchi H, Saito $\mathrm{Y}$, et al. Freeze-fracture electron microscopic and calorimetric studies on microscopic states of surface-modified liposomes with poly(ethylene glycol) chains. Colloids Surfaces B Biointerfaces. 2000; 17:275-82.

92. Tristram-Nagle S, Nagle JF. Lipid bilayers: thermodynamics, structure, fluctuations, and interactions Chem Phys Lipids. 2004;3-14.
93. Sainz MC, Chantres JR, Elorza B, Elorza MA. DSC study of the action of phenylbutazone on phospholipid phase transitions. Int J Pharm. 1993;91:1-8.

94. Kastantin M, Ananthanarayanan B, Karmali P, Ruoslahti E, Tirrell M. Effect of the lipid chain melting transition on the stability of DSPE-PEG(2000) micelles. Langmuir. 2009;25:7279-86.

95. Malinin VS, Frederik P, Lentz BR. Osmotic and curvature stress affect PEG-induced fusion of lipid vesicles but not mixing of their lipids. Biophys J. 2002;82:2090-100.

96. Perkins WR, Li X, Slater JL, Harmon PA, Ahl PL, Minchey SR, et al. Solute-induced shift of phase transition temperature in Disaturated PC liposomes: Adoption of ripple phase creates osmotic stress. Biochim Biophys Acta - Biomembr. 1997;1327:41-51.

97. Naumann C, Brumm T, Bayerl TM. Phase transition behavior of single phosphatidylcholine bilayers on a solid spherical support studied by DSC. NMR and FT-IR Biophys J. 1992;63:1314-9.

98. Monteiro N, Martins A, Reis RL, Neves NM. Liposomes in tissue engineering and regenerative medicine. J R Soc Interface. 2014;11:20140459.

99. Pozzi D, Colapicchioni V, Caracciolo G, Piovesana S, Capriotti AL, Palchetti S, et al. Effect of polyethyleneglycol (PEG) chain length on the bio-nano- interactions between PEGylated lipid nanoparticles and biological fluids: From nanostructure to uptake in cancer cells. Nanoscale. 2014;6:2782-92.

100. Erasmus JH, Khandhar AP, Walls AC, Hemann EA, O'Connor MA, Murapa $P$, et al. Single-dose replicating RNA vaccine induces neutralizing antibodies against SARS-CoV-2 in nonhuman primates. bioRxiv. 2020

101. Folegatti PM, Ewer KJ, Aley PK, Angus B, Becker S, Belij-Rammerstorfer $\mathrm{S}$, et al. Safety and immunogenicity of the ChAdOx1 nCoV-19 vaccine against SARS-CoV-2: a preliminary report of a phase 1/2, single-blind, randomised controlled trial. Lancet. 2020;396:467-78.

102. Erasmus JH, Khandhar AP, O'Connor MA, Walls AC, Hemann EA, Murapa P, et al. An Alphavirus-derived replicon RNA vaccine induces SARS-CoV-2 neutralizing antibody and T cell responses in mice and nonhuman primates. Sci Transl Med. 2020;12:9396.

103. Bulula N, Mwiru DP, Swalehe O, Thomas MA. Vaccine storage and distribution between expanded program on immunization and medical store department in Tanzania: a cost-minimization analysis. Vaccine. 2020;38:8130-5.

104. Chen D, Kristensen D. Opportunities and challenges of developing thermostable vaccines. Expert Rev Vaccines.2009;547-57.

105. Kim YC, Quan FS, Compans RW, Kang SM, Prausnitz MR. Stability kinetics of influenza vaccine coated onto microneedles during drying and storage. Pharm Res. 2011;28:135-44.

106. Pelliccia M, Andreozzi P, Paulose J, D’Alicarnasso M, Cagno $\mathrm{V}$, Donalisio $\mathrm{M}$, et al. Additives for vaccine storage to improve thermal stability of adenoviruses from hours to months. Nat Commun. 2016;7:13520.

107. Shin WJ, Hara D, Gbormittah F, Chang H, Chang BS, Jung JU. Development of thermostable lyophilized sabin inactivated poliovirus vaccine. MBio. 2018;9.

Publisher's Note Springer Nature remains neutral with regard to jurisdictional claims in published maps and institutional affiliations. 